\title{
DE NORTE A SUL: UMA ANÁLISE SOBRE AS CARACTERÍSTICAS ECONÔMICAS E GASTRONÔMICAS DAS PRINCIPAIS FRUTAS IDENTITÁRIAS NO BRASIL
}

\author{
Gabriela Ferreira Rodrigues \\ Universidade Federal Rural de Pernambuco, UFRPE, Brasil \\ gabriela.frodriguess@gmail.com \\ Aline Gomes Santana \\ Universidade Federal Rural de Pernambuco, UFRPE, Brasil \\ alinegsan157@gmail.com \\ Neide Kazue Sakugawa Shinohara \\ Universidade Federal Rural de Pernambuco, UFRPE, Brasil \\ neide.shinohara@ufrpe.br
}

\begin{abstract}
RESUMO
O presente estudo surge com o intuito de analisar as características de algumas frutas no território brasileiro sob a perspectiva do consumo, economia e versatilidade gastronômica. Foram selecionadas as frutas pequi, butiá, jabuticaba, caju e açaí, visto a representatividade de cada uma nas cinco regiões do Brasil. Além destas frutas também analisamos as características da banana, por estar presente no consumo frutífero de todas as regiões observadas. A partir de estudos bibliográficos, associados à coleta de dados no campo virtual através do método netnográfico, a pesquisa busca compreender e apresentar um pouco mais sobre cada uma das frutas ancorando-se em autores como Steele, Mourão e Fagundes além de dados de fontes como IBGE e Embrapa. Conforme as informações coletadas ao longo do estudo, consegue-se perceber a relevância destas frutas para o crescimento econômico da sua região de origem através de seu consumo que ocorre de diversas formas, sendo estimulado principalmente pela potencialidade e versatilidade gastronômica que estas oferecem. 0 estudo ainda traz uma breve observação da manifestação das frutas estudadas diante do cenário pandêmico em que o mundo se encontra, decorrente da propagação da Covid-19. Dessa forma, reforça a importância das frutas como elemento agregador e fortalecimento econômico para o mercado nacional.
\end{abstract}

Palavras-chave: Fruticultura. Consumo. Economia. Versatilidade. Pandemia. 


\title{
FROM NORTH TO SOUTH: AN ANALYSIS ON THE ECONOMIC AND GASTRONOMIC ASPECTS OF THE MOST CHARACTERISTIC FRUITS IN BRAZIL
}

\begin{abstract}
The present study aims to analyze the characteristics of some Brazilian fruits from the perspective of consumption, economy, and gastronomic versatility. Five specific fruits were selected, namely pequi, butiá, jabuticaba, caju, and açaí. These fruits were chosen considering the representativeness of each of these in the five Brazilian regions. In addition to these fruits, we also analyzed the characteristics of the banana, as it is present in the fruit consumption of all the observed regions. Based on bibliographic studies associated with data collection in the virtual field through the netnographic method, the research seeks to understand and shed some light on each of these fruits. Anchoring on authors such as Steele, Mourão and Fagundes besides data from sources such as IBGE and Embrapa. From the information collected throughout the study, we can claim the relevance of these fruits for the economic growth of their region of origin through their consumption that occurs in different ways, being stimulated mainly by the gastronomic versatility that they offer. The study also brings a brief observation on the manifestation of these fruits considering the pandemic which we are in due to the Covid-19 outbreak. Therefore, reinforcing the importance of fruits for the national fruit market.
\end{abstract}

Keywords: Fruit farming. Consumption. Economy. Versatility. Pandemic. 


\section{INTRODUÇÃO}

Falar de comes e bebes no território brasileiro engloba diversos segmentos, onde cada Estado da federação possui seus pratos tradicionais baseados em ingredientes típicos, sendo estes nativos e adotados, isso porque, o Brasil é um país continental que possui diversas culturas, sendo uma mistura entre tradições dos imigrantes, dos colonizadores, das pessoas escravizadas e dos povos indígenas. Com isso, cada região apresenta características únicas, pois, além da variedade de recursos naturais, a influência desses povos difere de acordo com o local. No entanto, como nação, há sim elementos que unem o país, como por exemplo as frutas, que tomam forma de bebidas e comidas (doce e salgado) estando presentes em todo território nacional.

A diversidade de florestas espalhadas pelos diferentes ecossistemas encontrados no Brasil, influencia diretamente no potencial frutífero do país. Segundo a Food and Agriculture Organization of the United Nations (FAO), conforme dados elaborados pelo Departamento de Economia da Secretaria de Agricultura e Abastecimento e o Departamento de Economia Rural do Paraná, o Brasil, em 2017, se encontrava como o terceiro maior produtor de frutas no mundo, sendo sua produção majoritariamente voltada para o comércio interno e com foco na Laranja, Banana e Abacaxi (ANDRADE, 2020). Além dessas frutas, há também no território brasileiro uma vasta quantidade de espécies pouco conhecidas e comercializadas, mas que compõem a alimentação diária das pessoas mais vulneráveis, minimizando a insegurança alimentar.

Inseridos no contexto da pandemia do novo coronavírus, desde 2020, os brasileiros vêm aumentando cada vez mais o consumo de frutas na sua dieta. De acordo com Steele et al. (2020), após uma pesquisa realizada com 10 mil pessoas de todas as regiões do país sobre os hábitos alimentares antes e durante a pandemia, observou-se um aumento na frequência de consumo de frutas, passando de $78,3 \%$ para $81,8 \%$.

Como existe uma grande disponibilidade de frutas no país, em espécies e quantidade, a exploração gastronômica deste grupo de alimento aumenta a cada ano. As frutas apresentam uma enorme versatilidade, sendo consumidas como bebida e/ou comida, 
passando por pratos salgados e doces, como acompanhante e até ingrediente principal, sendo aproveitada todas as partes comestíveis que a fruta oferece.

Neste contexto, o presente artigo traz uma discussão acerca de cinco frutas nativas do Brasil, açaí, caju, pequi, jabuticaba e butiá, e uma estrangeira, a banana. Tais frutas apresentam características comerciais e alimentícias diferentes, sendo cada uma delas representante de uma das 5 diferentes regiões do Brasil, norte, nordeste, centro-oeste, sudeste e sul, respectivamente. Já a banana se apresenta como a fruta mais consumida no país e vem como alimento que une os territórios de norte a sul. Desse modo, o objetivo do estudo foi analisar as seis frutas sob a perspectiva do consumo, em relação a sua importância na economia regional e nacional e sua versatilidade no uso gastronômico. Junto a isso, relacionamos tais aspectos culturais ao cenário atual de enfrentamento ao surto do covid-19 no Brasil.

Como método de estudo, diante da abrangência do tema, foi usada a netnografia e a pesquisa bibliográfica. Kozinets (2014, p. 62), define a netnografia como um meio que "usa comunicações mediadas por computador como fonte de dados para chegar à compreensão e à representação etnográfica de um fenômeno cultural ou comunal". Desse modo, foi possível, com base em textos escritos, imagens, fotos, áudios e vídeos, analisar com maior profundidade a forma de consumo das seis frutas nas regiões que são cultivadas. Ademais, a consulta em site e portais do governo dos Estados e das prefeituras foi de extremo valor, agregando dados e informações locais. Somada à netnografia, a pesquisa bibliográfica permitiu investigar o material já disponível acerca da temática, onde exploramos estudos científicos relacionados às frutas supracitadas.

\section{PROPRIEDADES E CARACTERÍSTICAS DAS FRUTAS}

Cada fruta citada neste artigo, possui propriedades e características únicas, tais como clima e solo em que são cultivadas, período de frutificação, tamanho e composição 
nutricional. Esses atributos interferem diretamente e indiretamente no consumo, na economia e no uso gastronômico.

Uma das frutas típicas do território brasileiro é o açaí, do tupi "yasa'i", oriundo da região norte $\mathrm{O}$ açaizeiro, nomeado cientificamente como Euterpe oleracea, é a árvore que dá origem ao açaí e que também fornece o palmito. Tal frutífera é predominante em solos de várzea baixa e locais que possuem clima quente e úmido, produzindo maior volume de açaí no segundo semestre do ano, apesar de frutificar durante o ano todo. Segundo Mourão (2010), a palmeira do açaí apresenta um estipe (caule) que atinge de 10 a 35 metros de altura. Além disso, o açaí possui alto valor calórico e se destaca pela riqueza de proteínas e, principalmente, lipídios.

O cajueiro (Anacardium occidentale) é uma planta cultivada em larga escala na região Nordeste do Brasil. Dessa árvore tem-se a castanha de caju, fruto (ovário desenvolvido) rico em proteínas e ácidos graxos poli-insaturados, e o caju, pseudofruto (tecido acessório que se desenvolve associado ao verdadeiro fruto) ou pedúnculo (haste ou tecido acessório que sustenta o fruto) abundante em açúcares, vitamina C e minerais (PAIVA et al., 2000). Segundo Crisóstomo et al. (2003), o cajueiro vem sendo dividido e estudado em dois grupos, o comum, é mais difundido e possui uma altura de 8 a 15 metros, e o anão, que atinge tamanhos inferiores a 4 metros. Para o cultivo, é recomendado uma área de clima tropical e com solo profundo, bem drenado e com boa reserva de nutrientes. Conforme Serrano e Pessoa (2016), a colheita de caju se dá no Estado do Ceará, principal produtor do Caju no país, entre outubro e novembro.

Nativo do cerrado, o pequi, segundo Soares (2018, p.9), tem seu valor nutricional "constituído por lipídios, proteínas, carboidratos, fibra alimentar, carotenóides e vitamina C". A fruta é proveniente do pequizeiro (Caryocar brasiliense Camb.), que necessita de um clima tropical ou subtropical para frutificar. Além disso, no estudo, de Santana e Naves (2007), realizado em vinte áreas do cerrado com predominância de pequizeiro, é relatada maior 
ocorrência da planta em regiões com solo de baixa fertilidade, destacando o cambissolo ${ }^{1}$ e o litossolo ${ }^{2}$. Com todas as condições de cultivo, ainda de acordo com Soares (2018), a árvore do pequi atinge até 10 metros de altura e a colheita dos frutos ocorre entre outubro e fevereiro na região do cerrado.

A jabuticaba, conhecida regionalmente como ouro negro, é um fruto globoso preto com polpa esbranquiçada. Conforme Lage et al. (2017), seu nome vem do tupi guarani "iapoti'ka", que significa "fruta botão", sua safra acontece nas estações da primavera e do verão e a jabuticabeira chega a atingir até 15 metros de altura. Para além disso, ela possui algumas variedades no Brasil, como a jabuticaba Sabará (Myrciaria jabuticaba) e a jabuticaba Paulista (Myrciaria cauliflora). Apesar de possuírem composições químicas diferentes, em geral a jabuticaba se apresenta "como fonte alternativa de minerais principalmente ferro, potássio, magnésio e manganês assim como de açúcares e ácidos orgânicos e vitamina C", de acordo com Lima (2009, p.97).

Nativa da região Sul do Brasil, do Paraguai e da Argentina, o butiazeiro é uma palmeira que dá frutos, de tons amarelos e polpas fibrosas, chamados de butiá. Segundo Patro (2014), o fruto é rico em betacaroteno, vitamina A e C. Se tratando do cultivo, o butiazeiro aprecia locais de clima subtropical e com solos drenados e ricos em matéria orgânica (PATRO, 2014). Desse modo, a partir das condições ideais, a árvore chega a produzir $20 \mathrm{~kg}$ de butiás por cachos, entre dezembro e fevereiro (EMBRAPA, 2019).

Vinda da Ásia, a banana (Musa spp.) foi trazida pelos colonizadores portugueses para o Brasil, e logo se adaptou aos diversos climas e solos do país (BARROS et al. 2016), sendo uma fruta bastante apreciada pelos brabarrosborgessileiros. Rico em carboidratos e potássio, este fruto possui uma extensa variedade de espécies como nanica, maçã, da terra, ouro e prata. É por essa diversidade que, segundo Barros et al. (2016), o tamanho da árvore pode variar de

\footnotetext{
${ }^{1}$ Tipo de solo constituído por material mineral e com o horizonte B ainda não transformado totalmente (SANTOS et al., 2018).

2 O litossolo é uma das subordens do Neossolo, caracterizado por ser um com pouca espessura de material orgânico ou muita matéria mineral e apresenta pouca ou nenhuma diferença em relação ao material originário (SANTOS et al., 2018).
} 
1,5 a 8 metros de altura. Assim como o comprimento, a época de colheita varia conforme a espécie e também de acordo com outros fatores como clima e período do plantio.

As frutas, cada uma com sua particularidade, se apresentam como uma ótima fonte de vitaminas, minerais, carboidratos, lipídios, proteínas e água. Desse modo, é recomendado, pelo guia alimentar para a população brasileira (BRASIL, 2014). O consumo diário desse alimento, que contribui para a prevenção de muitas doenças. Por essas e outras razões que as frutas estão sendo mais consumidas, no Brasil, durante a pandemia do covid-19 (STEELE et al., 2020).

\section{ECONOMIA REGIONAL E NACIONAL}

A fruticultura é um dos setores mais importantes na atualidade para a geração de receita, empregos, e principalmente, alimentos no Brasil. De acordo com dados divulgados em 2020 do Centro de Estudos Avançados em Economia Aplicada-CEPEA/USP em parceria com a Confederação da Agricultura e Pecuária do Brasil-CNA, o agronegócio, setor econômico que a fruticultura compõe, contribui em $21,4 \%$ no PIB brasileiro, gerando uma receita de $\mathrm{R} \$ 1,55$ trilhão em 2019 (CNA, 2020). Sendo que, 16\% da mão de obra do agronegócio é destinado à área frutícola, segundo a Associação Brasileira dos Produtores Exportadores de Frutas e Derivados- ABRAFRUTAS (2019).

Apesar de o Brasil ser o terceiro maior produtor de frutas no mundo, ele ainda destina a maior parte da produção para o mercado interno. No ano de 2019, o país ocupava a posição de 23 ㅇ lugar no ranking mundial, no quesito de exportação desses produtos, com cerca de 3\% da produção nacional destinada ao mercado externo (ABRAFRUTAS, 2019).

Dentro desse cenário, as frutas evidenciadas neste texto apresentam-se como figuras relevantes para a fruticultura por seus valores e protagonismo comercial em escala nacional e/ou local. Reforçando assim a ideia de Rufino (2008, p.5), ao pontuar que "a importância econômica das fruteiras para as diversas regiões do Brasil não pode ser mensurada apenas 
por dados estatísticos [visto que], essa atividade é uma das principais geradoras de renda, de empregos e desenvolvimento regional".

O açaí tem sua produção centralizada na região norte do Brasil. O maior produtor de do fruto no mundo é o Estado do Pará, seguido pelo Amazonas e pelo Maranhão (SERRA; SANTOS, 2021). Da região norte, o açaí é distribuído ao longo do Brasil. Ainda segundo os mesmos autores, de acordo com os dados entregues ao G1, em 2019, pelo Sindicato das Indústrias de Frutas e Derivados, o açaí do Pará movimenta em torno de 1,5 bilhão de dólares na economia estadual e, saindo do território paraense, a fruta se destina principalmente a São Paulo, Rio de Janeiro e Minas Gerais. Apesar de possuir grande repercussão em território brasileiro, o açaí vem conquistando cada vez mais o mercado externo. Atualmente, os Estados Unidos da América é o principal país importador da fruta, correspondendo a $66 \%$ do total exportado pelo Brasil, segundo Serra e Santos (2021).

Com 62,9\% da produção nacional em 2019, o Ceará é o principal estado produtor de castanha de caju no Brasil, seguido pelo Piauí e pelo Rio Grande do Norte (FAGUNDES, 2020). Apesar da expressiva quantidade produzida pelo Brasil, de acordo com a FAO (2020), o país que se destacou na produção mundial de castanha de caju com casca, em 2019, foi a Costa do Marfim. Ainda segundo Fagundes (2020), o Brasil exportou, entre janeiro e novembro de 2020, 14,6 mil toneladas de castanha de caju sem casca com destino, principalmente, aos Estados Unidos, Alemanha e Holanda.

O pequi, por sua vez, possui sua produção centralizada em Minas Gerais, com cerca de 18 mil toneladas do fruto em 2019, seguido pelo Tocantins e Goiás, segundo o Instituto Brasileiro de Geografia e Estatística-IBGE, (2020). Apesar disso, é notável a relevância do pequi para a região centro-oeste, principalmente no Estado de Goiás, pela presença na culinária local. O pequi se mostra extremamente importante na economia local, é o que afirma Ribeiro $(2013, s / p)$ :

[...]o fruto símbolo do cerrado era a garantia de alimentação durante o período da safra. Agora, o dinheiro que resulta das vendas do pequi também proporciona a 
compra de roupas, eletrodomésticos e outros bens de consumo, ajudando centenas de pessoas a amenizar o castigo da seca.

Em 2017, o maior produtor de Jabuticaba no país era o Estado de Goiás, com cerca de 1,7 mil toneladas, acompanhado por São Paulo e Minas Gerais, de acordo com o IBGE (2017). No cenário geral do Brasil, foi colhido, em 2017, aproximadamente de 3,7 mil toneladas de jabuticaba, gerando um valor de 10,5 milhões de reais (IBGE, 2017). Além disso, a fruta tem grande influência na economia local de algumas cidades. No município de Sabará, em Minas Gerais, gera-se uma circulação de renda de cerca de $\mathrm{R} \$ 5$ milhões durante os quatros dias do Festival de Jabuticaba da cidade (PATRÍCIO, 2020).

Fruto típico do Rio Grande do Sul, o Butiá é bastante comum na região sul do Brasil. Por ser um fruto ainda pouco comercial nacionalmente, os moradores de Santa Vitória do Palmar usam das folhas e frutos do butiazeiro para produzir receitas e artesanato, comercializando-os no mercado local e gerando uma renda extra para a família (TRZECIAK, 2012). Além disso, há 13 edições ocorre a Feira do Butiá na cidade de Giruá-RS, que movimenta a economia local trazendo produtos artesanais feitos com o butiá (GIRUÁ, 2019)

Além das frutas de cada região, tem-se a banana que se apresenta como um destaque na produção, tanto em escala nacional quanto mundial. Segundo o IBGE (2021), em 2020, o Brasil produziu cerca de 6,7 milhões de toneladas de banana, onde São Paulo foi o Estado que mais se destacou, seguido pela Bahia e por Minas Gerais. Ainda em 2020, o Brasil enviou para o mercado exterior, cerca de 84 mil toneladas de banana, de acordo com a ABRAFRUTAS (2021). Comparando os dados acima, é possível afirmar que a maior parte do que é produzido de banana no país é mantido no mercado interno. Mundialmente, a Índia se destaca na produção da fruta com 30 milhões de toneladas no ano de 2019 e ocupando segundo e terceiro lugar no ranking tem-se China e Brasil, respectivamente (FAO, 2020).

Com a pandemia do covid-19, muitos setores econômicos foram atingidos, sendo a fruticultura um deles. As frutas citadas no artigo foram impactadas de diferentes formas durante esse período. O açaí, segundo Serra e Santos (2021), teve queda nas exportações e o preço pago ao produtor foi menor no primeiro semestre de 2020 em relação ao mesmo período no ano anterior. Com o caju foi um pouco diferente, até novembro de 2020, o Brasil 
apresentou uma redução de $4 \%$ na quantidade exportada da fruta, mas o preço médio recebido pelo produtor aumentou em 32\% no décimo primeiro mês daquele ano, comparado ao ano de 2019 (FAGUNDES, 2020).

Mesmo com os preços mais baixos em 2020, a procura de pequi na região do Cariri, onde é muito consumido, diminuiu bastante segundo Rodrigues (2021), por conta da pandemia. Já com o butiá, o prejuízo se refletiu na feira da fruta, que teve que ser suspensa (GIRUÁ, 2020). Outro evento que foi impactado foi o Festival de Jabuticaba de Sabará que, apesar de ter acontecido remotamente, não teve o mesmo faturamento do ano de 2019 (PATRÍCIO, 2020). Em oposição aos casos citados, tem-se a banana que enviou para o mercado externo $5 \%$ a mais em quantidade e, somado a isso, o cenário nacional produziu mais de um milhão de toneladas de frutas, representando um crescimento de $6 \%$ no setor da exportação, em 2020 em comparação ao ano anterior (ABRAFRUTAS, 2021).

\section{CONSUMO E VERSATILIDADE GASTRONÔMICA}

O Brasil é um país com extensão continental, trazendo consigo alta diversidade de climas e solos. Desse modo, ao longo do seu território são produzidos e consumidos diferentes tipos de frutas. A gastronomia inclui saberes e fazeres na perspectiva de conservação, transformação e proteção de recursos alimentares locais à disposição das comunidades, que com o emprego de técnicas culinárias adequadas podem prolongar a oferta de frutas em preparações doces, salgadas, assim como sucos e bebidas.

Originalmente, o açaí é consumido pelas comunidades ribeirinhas do estuário amazônico. Porém, conforme Rossini (2019), o açaí só começou a se popularizar em outras regiões do Brasil, que não somente na região Norte, a partir da virada do milênio. Ao sair da sua região de origem, o fruto teve que sofrer adaptações para conseguir chegar sem oferecer um risco à saúde do consumidor, sendo feita a industrialização e congelamento da polpa (ROSSINI, 2019). Com isso, o açaí é consumido de diferentes formas ao longo do país, como diz Mourão (2010, p.84):

O açaí com farinha de mandioca acompanhado de uma proteína animal (carne, peixe e camarão fritos ou moqueados) constitui-se ainda na principal refeição das populações mais pobres do mundo urbano e rural na Amazônia. Com açúcar ou adoçante é um delicioso suco, ingerido como sobremesa ou lanche. Cozido com 
arroz, tapioca ou pasta de farinha puba é um nutritivo componente do café da manhã. Acrescente a estas modalidades de consumo os sorvetes, os cremes, mousses, pudins licores e bebidas alcoólicas como a cachaça e o vinho fermentado a semelhança da uva.

Muito comum na culinária nordestina, o caju oferece infinitas possibilidades de pratos doces e salgados tanto para o fruto quanto para o pedúnculo. Como bebida, o pseudofruto se apresenta combinado a destilados para drinks, como polpa para sucos e vinhos, e da sua castanha podemos fazer leites e queijos. Além disso, como patrimônio tombado pela Unesco juntamente ao IPHAN temos a Cajuína, bebida não alcoólica tradicional piauiense (SOUZA, 2018). Integrando pratos e refeições, o caju explora os limites da criatividade do cozinheiro. Com a castanha pode-se fazer farofas, bolos e pastas. Já com o pedúnculo, é possível elaborar geleias, compotas, mariolas (doce feito com banana, caju ou goiaba) rapaduras e doces em calda. Além disso, a carne de caju é uma ótima opção para substituir a proteína animal. Assim explica o chef Claudemir Barros na matéria de Souza (2018, s/p):

Mas ele [o caju] vai além. Se você olhar para a história, verá que, por décadas, serviu como proteína principal. A minha mãe fazia bife de caju sem a gente saber o que era. Ela aprendeu isso com minha avó e assim sucessivamente. Então, quantas receitas não existem à base da 'fruta brasileira'?

Nativo do cerrado brasileiro e fruta típica do Centro-Oeste, o pequi possui um sabor único e se constitui como base alimentar da população desse bioma. Diversos pratos regionais e tradicionais exaltam essa fruta, como por exemplo o Lagarto com Pequi, Arroz com Pequi, Frango com Pequi e até sendo o ingrediente principal como a Pequizada. Na forma de bebida, o pequi dá um excelente coquetel, se associado ao mel e à cachaça, e serve também um belo licor. Para além da alimentação, de acordo com Soares (2018), o pequi tem uso cosmético e medicinal, com propriedades antioxidantes e anti-inflamatória.

A jabuticaba é originária da Mata Atlântica, porém tem sua produção acentuada na região Sudeste e Centro-Oeste do país. Como a fruta é perecível e a árvore floresce poucas vezes ao ano, as populações locais exploram as infinitas possibilidades de elaborar os derivados da jabuticaba. Tamanha é a importância dessa fruta que em 2020 o Festival da Jabuticaba de Sabará completou 34 edições (VELOSO, 2020). Molhos, sorvetes, licores, 
jabuticabada, geleias, farinhas, cervejas, conhaque, pães e até mortadela da fruta são alguns exemplos da versatilidade que jabuticaba possui, até o momento.

Comumente encontrada no Estado do Rio Grande do Sul, o butiá atrai não somente os olhares humanos, mas também a fauna silvestre local, garantindo uma ótima fonte de energia para esses animais (PATRO, 2014). Na alimentação, o butiá ganha formas de recheio, sucos, rapadura, geleias, licores, bolos, sorvetes e mousses. Segundo Büttow et al. (2009), além do consumo in natura, a fruta também integra pratos como "Arroz com butiá" e possui uma amêndoa que é uma semente comestível.

A banana, musa do Brasil, é a fruta mais consumida no país (BORGES et al., 2015). Tal alimento apresenta praticidades particulares, como por exemplo a casca que é uma embalagem perfeita. Para além do consumo in natura no dia a dia, a banana é ingerida em pratos salgados na forma de nhoque, chips, farofa e em tortas. Já em pratos doces, a fruta possui grande abrangência, integrando bolos, tortas e sorvetes, além da própria bananada, da mariola e nego bom. Tradicional da cozinha brasileira, a cartola é uma sobremesa típica do Nordeste que leva banana, queijo, açúcar e canela. A fruta, também é uma ótima opção vegana, possibilitando o consumo da carne de casca de banana.

Considerando-se o contexto de pandemia da covid-19 enfrentado atualmente no Brasil, é de extrema importância destacar a necessidade do consumo de frutas, pelas propriedades nutricionais fornecidas. Em entrevista para Malavé (2020), Wanessa Marinho, coordenadora do Núcleo de Alimentação, Saúde e Ambiente (Nasa) da Fiocruz, e Débora Oliveira, nutricionista do Nasa, esclarecem que "até o momento, não há nenhum medicamento, substância, vitamina, alimento específico ou vacina que possa prevenir e/ou curar a infecção pelo novo coronavírus.". Apesar disso, fortalecer o sistema imunológico e manter uma alimentação saudável se torna um fator útil na hora do combate ao vírus (MALAVÉ, 2020).

Para o bom funcionamento do sistema imune é preciso ter uma dieta equilibrada entre macro e micronutriente. A partir do que foi relatado nos parágrafos anteriores, é possível afirmar que as frutas citadas possuem, cada uma com sua singularidade, os nutrientes para, 
junto a outros alimentos, garantir um bom funcionamento do organismo e do nosso sistema de defesa.

\section{CONCLUSÃO}

A partir das informações coletadas, é possível perceber que as frutas citadas no artigo apresentam características diferentes, entre elas, no setor econômico, na área do consumo e em suas propriedades nutricionais. Apesar disso, todas têm sua importância dietética, econômica e gastronômica, seja em escala regional, nacional e até mundial.

O açaí e o caju mostraram como as frutas nacionais conseguiram conquistar o paladar estrangeiro. Esse primeiro teve que sofrer adaptações para o comércio fora da região produtora, com o processo de congelamento da polpa e adição de conservantes e adoçantes, onde cada país tem sua prioridade quanto à proporção destes componentes. Já o caju expandiu de maneira a ser até produzido em outras regiões do planeta, superando os números do Brasil nesse setor.

No que se refere à banana o processo foi inverso, essa fruta estrangeira é a mais apreciada pelo brasileiro compondo receitas tradicionais do país, além de possuir protagonismo no Brasil como importante produto de exportação mundial.

Quanto a jabuticaba e o pequi, observou-se uma certa ambiguidade, em razão de que ambos apontam uma produtividade em uma região diferente daquela onde são mais consumidas, tendo grande importância cultural e gastronômica por onde transitam. Desse modo, fica explícito como ao longo dos anos a fruticultura brasileira expandiu para além das fronteiras regionais.

Ao longo da pesquisa, foi perceptível que o butiá ainda possui poucas informações disponíveis, podendo ser um reflexo do baixo protagonismo nacional. Entretanto, a fruta apresenta grande relevância na região sul do país, compondo até ditos populares como "cair os butiás do bolso".

É possível analisar também, a importância de festivais gastronômicos nas regiões produtoras dessas frutas. A jabuticaba e o butiá são um exemplo claro de como tais eventos 
podem movimentar a economia local, além de exaltar o potencial da fruta e estimular a criatividade dos comerciantes na produção de derivados.

Entretanto, com a pandemia do novo coronavírus, a comercialização e o consumo dessas frutas foram diretamente afetados. No que se refere ao consumo, ainda que a exportação, no setor frutífero, no Brasil tenha aumentado significativamente no ano de 2020, cada fruta se comportou de um jeito diante desse cenário. Enquanto a banana aumentou expressivamente na exportação, o açaí teve uma redução de $4 \%$. Já para as frutas pouco comerciais (pequi, jabuticaba e butiá) foi relatada uma queda na procura e na comercialização, que pode ter sido influenciada pelo fechamento dos comércios, pelo cancelamento ou adaptações dos festivais e pelas medidas de isolamento social. Quanto ao consumo, vemos a importância da ingestão desses alimentos, ainda mais num contexto de crise sanitária. Sendo assim, é de extrema relevância que a população continue aumentando o uso das frutas na alimentação diária conforme sugere Steele et al. (2020).

A diversidade brasileira enriquece nossa cultura e tradições. Cada região do país possui suas particularidades e dentro do potencial frutífero do Brasil, ainda há muito a ser explorado e descoberto.Além disso, muitas dessas frutas são extremamente relevantes como fonte de alimento e bebida para populações locais e de baixa renda.

Deste modo, a partir do estudo das frutas apresentadas no texto, podemos perceber como a fruticultura é relevante para economia nacional, e como o consumo das frutas nas mais diferentes formas contribui para o enriquecimento do campo gastronômico, por sua versatilidade, e para o desenvolvimento das diferentes regiões do Brasil.

\section{REFERÊNCIAS}

ANDRADE, P. F. S. Fruticultura. Governo do Estado do Paraná, Secretaria da Agricultura e do Abastecimento, 2020. Disponível em: <http://www.agricultura.pr.gov.br/sites/default/arquivos_restritos/files/documento/202001/fruticultura_2020.pdf>. Acesso em: 13 de fev. de 2021.

Associação Brasileira dos Produtores Exportadores de Frutas e Derivados. Brasil é o terceiro maior produtor de frutas do mundo, diz Abrafrutas. Brasília, 7 mar. 2019. Disponível em: 
<https://abrafrutas.org/2019/03/brasil-e-o-terceiro-maior-produtor-de-frutas-do-mundodiz-abrafrutas/> . Acesso em 15 de mar. de 2021.

Associação Brasileira dos Produtores Exportadores de Frutas e Derivados. Dados de Exportação 2020. Brasília, 2021. Disponível em:<https://abrafrutas.org/2021/02/dados-deexportacao-2020/>. Acesso em 15 de mar. de 2021.

BARROS, E. C. da D.; INÁCIO, R. A.; PINTO, F. O.; QUINTAS, E. da S.; RODRIGUES, M. D. A utilização da banana como fonte de renda para pequenos produtores. Revista Científica Interdisciplinar, $\quad$ v. $3, \quad$ n. $\quad 2, \quad$ p.22-37, $2016 . \quad$ Disponível em:<http://revista.srvroot.com/linkscienceplace/index.php/linkscienceplace/article/view/23 8>. Acesso em 09 de mar. de 2021.

BORGES, A. L.; MATOS, A. P. de; RITZINGER, C. H. S. P.; SOUZA, L. da S.; LIMA, M. B.; FANCELLI, M. Boas práticas agrícolas de campo no cultivo da bananeira.Cruz das Almas, BA: Embrapa Mandioca e Fruticultura, 52p., $2015 . \quad$ Disponível em : <https://www.infoteca.cnptia.embrapa.br/infoteca/handle/doc/1015213>. Acesso em : 17 de mar. de 2021.

BRASIL. Ministério da Saúde . Guia alimentar para a população brasileira: promovendo a alimentação saudável. 2o ed. Brasília, Ministério da Saúde, 2014. Disponível em: $<$ https://bvsms.saude.gov.br/bvs/publicacoes/guia_alimentar_populacao_brasileira_2ed.pd >. Acesso em 09 de mar. de 2021.

BÜTTOW, M. V.; BARBIERI, R. L.; NEITZKE, R. S.; HEIDEN, G. Conhecimento tradicional associado ao uso de Butiás (Butiá spp., Arecaceae) no sul do Brasil. Rev. Bras. Frutic., Jaboticabal, v. 31, n. 4, p. 1069-1075, dez. 2009. Disponível em:<https://www.scielo.br/pdf/rbf/v31n4/v31n4a21.pdf>. Acesso em: 11 de fev. de 2021 Confederação da Agricultura e Pecuária do Brasil-CNA. Panorama Agro. Brasília, jun. 2020. Disponível em: <https://www.cnabrasil.org.br/cna/panorama-do-agro\#_ftn1>. Acesso em: 27 de fev. de 2021.

CRISÓSTOMO, L. A.; SANTOS, F. J. de S.; OLIVEIRA, V. H. de; RAIJ, B. van; BERNARDI, A. C. de C.; SILVA, C. A.; SOARES, I. Cultivo do cajueiro anão precoce: aspectos fitotécnicos com ênfase na adubação e na irrigação.Fortaleza: Embrapa Agroindústria Tropical, out. 2003. Disponível em: <https://www.embrapa.br/busca-de-publicacoes/-/publicacao/424408/cultivo-docajueiro-anao-precoce-aspectos-fitotecnicos-com-enfase-na-adubacao-e-na-irrigacao >.

Acesso em: 08 de mar. de 2021.

EMBRAPA. Cuidados na colheita contribuem para longevidade do butiá. Brasília-DF: Embrapa Clima Temperado, 4 abr. 2019. Disponível em: <https://www.embrapa.br/busca-de-noticias//noticia/42442421/cuidados-na-colheita-contribuem-para-longevidade-do-butia>. Acesso em 09 de mar. de 2021.

FAGUNDES, M. H. Castanha de Caju - Análise Mensal - Novembro 2020.Brasília: Companhia Nacional de Abastecimento (CONAB), 14 dez. 2020. Disponível em: $<$ https://www.conab.gov.br/info-agro/analises-do-mercado-agropecuario-e- 
extrativista/analises-do-mercado/historico-mensal-de-castanha-de-caju>. Acesso em 15 de mar. de 2021.

FOOD AND AGRICULTURE ORGANIZATION OF THE UNITED NATIONS-FAO. FAOSTAT. Roma: FAO, 2020. Disponível em: <http://www.fao.org/faostat/en/\#data/QC> . Acesso em 15 de mar. de 2021.

GIRUÁ. Prefeitura Municipal de Giruá. Atrações artísticas da Expogiruá marcam a história do município. Giruá, $2019 . \quad$ Disponível em: <https://www.girua.rs.gov.br/site/noticias/expogirua/38442-atracoes-artisticas-daexpogirua-marcam-a-historia-do-municipio>. Acesso em 15 de mar. de 2021.

GIRUÁ. Prefeitura Municipal de Giruá. Município de Giruá suspende aulas até dia $\mathbf{2}$ de abril e transfere a 14a Feira do Butiá. Giruá, 2020. Disponível em: <https://www.girua.rs.gov.br/site/noticias/noticia/48327-municipio-de-girua-suspendeaulas-ate-dia-2-de-abril-e-transfere-a-14-feira-do-butia>. Acesso em 15 de abr. de 2021.

Instituto Brasileiro de Geografia e Estatística-IBGE. Censo agro 2017. Rio de Janeiro: IBGE, 2017.Disponível <https://censos.ibge.gov.br/agro/2017/templates/censo_agro/resultadosagro/agricultura.ht ml ?localidade=0\&tema=76309> . Acesso em 15 de mar. de 2021.

Instituto Brasileiro de Geografia e Estatística-IBGE. Levantamento Sistemático da Produção Agrícola: Estatística da Produção Agrícola janeiro 2021. Rio de Janeiro: IBGE, 2021. Disponível em: $<$ https://biblioteca.ibge.gov.br/index.php/bibliotecacatalogo?id=72415\&view=detalhes $>$. Acesso em 15 de mar. de 2021

Instituto Brasileiro de Geografia e Estatística-IBGE. Produção da Extração Vegetal e Silvicultura 2019. Rio de Janeiro: IBGE, 2020. Disponível em: <https://cidades.ibge.gov.br/brasil/go/pesquisa/16/12705?localidade1\%3D31\%26localidade 2\%3D23\%26indicador\%3D12722=\&sa=D\&source=editors\&ust $=1615764789696000 \& u s g=A O$ vVaw0Qg6sWu0vO4ySr_ItlkJuG\&localidade1=31\&localidade2=17>. Acesso em 15 de mar. de 2021

KOZINETS, R. V. Netnografia: realizando pesquisa etnográfica online. Porto Alegre: Penso, 2014.

LAGE, C. A.; CARDOSO, N.; CARMO, L. A. M.; ELIAS, M. A. A versatilidade do consumo da jabuticaba: descobrindo possibilidades de aproveitamento dessa fruta no dia a dia. CES REVISTA, Juiz de Fora, v. 1, n. p.116-132, 2017. Disponível em : $<$ https://docplayer.com.br/50941663-A-versatilidade-do-consumo-da-jabuticabadescobrindo.html >. Acesso em: 12 de fev. de 2021 (Mart.) O. Berg]. 2009. Tese (Doutorado em Agroquímica)-Universidade Federal de Lavras, 
Lavras,

MG.

Disponível

em:<http://repositorio.ufla.br/jspui/bitstream/1/2586/1/TESE_Caracteriza\%C3\%A7\%C3\%A3 o\%20e\%20atividade\%20antioxidante\%20da\%20jabuticaba\%20\%5BMyrciaria\%20cauliflora\% 20\%28Mart.\%29\%200.\%20Berg\%5D.pdf>. Acesso em 08 de mar. de 2021.

MALAVÉ, M. M. Especialistas tiram dúvidas sobre alimentação e coronavírus. Rio de Janeiro: Fiocruz, 15 maio 2020. Disponível em: <https://portal.fiocruz.br/noticia/especialistas-tiramduvidas-sobre-alimentacao-e-coronavirus >. Acesso em 09 de mar. de 2021.

MOURÃO, L. História e natureza: açaí ao palmito. Revista Territórios e Fronteiras, v.3 n.2, p.74-96, 2010. Disponível em: <http://www.ppghis.com/territorios\&fronteiras/index.php/v03n02/article/view/69/68>. Acesso em: 13 de fev. de 2021.

PAIVA, F. F. de A.; GARRUTI, D. dos S.; SILVA NETO, R. M. da. Aproveitamento Industrial do caju. Fortaleza: Embrapa-CNPAT/SEBRAE/CE, 88p., 2000. Disponível em:<https://www.embrapa.br/busca-de-publicacoes/-

/publicacao/0422033/aproveitamento-industrial-do-caju>. Acesso em 08 de mar. de 2021.

PATRÍCIO, E. Pandemia derruba festivais gastronômicos e economia de Sabará. Estado de Minas, 10 ago. 2020.2 Disponível em: <https://www.em.com.br/app/noticia/economia/2020/08/10/internas_economia,1174609/ pandemia-derruba-festivais-gastronomicos-e-economia-de-sabara.shtml $>$. Acesso em 15 de mar. de 2021.

PATRO, R. Butiá - Butia capitata. Jardineiro.net, 27 fev. 2014 . Disponível em:<https://www.jardineiro.net/plantas/butia-butia-capitata.html>.Acesso em: 11 de fev. de 2021.

RIBEIRO, L. Pequi vira ouro do cerrado. Estado de Minas, 15 jul. 2013 Disponível em: <https://www.em.com.br/app/noticia/economia/2013/07/15/internas_economia,422647/p equi-vira-ouro-do-cerrado.shtml >. Acesso em 15 de mar. de 2021.

RODRIGUES, A. Em plena safra, vendas de pequi caem no Cariri devido à pandemia. Diário do Nordeste, 262021.2 jan. 20 em: $<$ https://diariodonordeste.verdesmares.com.br/regiao/em-plena-safra-vendas-de-pequicaem-no-cariri-devido-a-pandemia-1.3038249> . Acesso em 15 de mar. de 2021.

ROSSINI, M. C. Como o açaí conquistou o mundo. Super Interessante, 2019. Disponível em: <https://super.abril.com.br/especiais/as-raizes-do-acai/ >. Acesso em 16 de mar. de 2021.

RUFINO, M. S. M. Prioridades funcionais de frutas tropicais brasileiras não tradicionais. 2008. Tese (Doutorado em Agronomia). Universidade Federal Rural do Semi Árido, Mossoró-RN. 
Disponível em: <https://ppgfito.ufersa.edu.br/wp-content/uploads/sites/45/2021/01/Tesede-Maria-do-S

ocorro-Rufino.pdf> .Acesso em: 11 de fev. de 2021.

SANTANA, J. DAS G.; NAVES, R. V. Caracterização de ambientes de cerrado com alta densidade de pequizeiros (Caryocar brasiliense Camb.) na região Sudeste do Estado de Goiás. Pesquisa Agropecuária Tropical, v. 33, n. 1, p. 1-10, 15 nov. 2007. Disponível em:<https://www.revistas.ufg.br/pat/article/view/2380>. Acesso em 08 de mar. de 2021.

SANTOS, H. G. dos; JACOMINE, P. K. T; ANJOS, L. H. C. dos; OLIVEIRA, V. A. de; LUMBRERAS, J. F.; COELHO, M. R.; ALMEIDA, J. A. de; ARAUJO FILHO, J. C. de; OLIVEIRA, J. B. de; CUNHA, T. J. F.. Sistema Brasileiro de Classificação de Solos. 5o. ed. Brasília, DF: Embrapa, 2018. 356 p. Disponível em :<https://www.embrapa.br/solos/sibcs >. Acesso em 09 de mar. de 2021.

SERRA, F. R.; SANTOS, D. Açaí - Análise Mensal - Dezembro 2020. Brasília: Companhia Nacional de Abastecimento (CONAB), 08 jan. 2021. Disponível em: $<$ https://www.conab.gov.br/info-agro/analises-do-mercado-agropecuario-eextrativista/analises-do-mercado/historico-mensal-de-acai > . Acesso em 15 de mar. de 2021.

SERRANO, L. A. L.; PESSOA, P. F. A. P. Aspectos econômicos da cultura do cajueiro. 2a ed. Rio de Janeiro: Embrapa Agroindústria Tropical, Sistema de Produção, jul. 2016. Disponível em: $<$ https://www.spo.cnptia.embrapa.br/conteudo?p_p_lifecycle=0\&p_p_id=conteudoportlet_ WAR_sistemasdeproducaolf6_1ga1ceportlet\&p_p_col_count $=1 \& p \_p \_c o l i d=c o l u m n-$ 2\&p_p_state $=$ normal\&p_r_p_-76293187_sistemaProducaold $=7705 \& p \_r \_p \_-$ 996514994_topicold=10308\&p_p_mode=view>. Acesso em 11 de mar. de 2021.

SOARES, C. T. Secagem da polpa de pequi por liofilização. 2018. Dissertação (mestrado) Universidade Estadual de Campinas, Faculdade de Engenharia Agrícola, Campinas-SP. Disponível em:<http://repositorio.unicamp.br/jspui/handle/REPOSIP/332599>. Acesso em 11 de mar. de 2021.

SOUZA, E. É tempo de caju na feira e no prato. Folha PE, 28 jul. 2018. Disponível em : $<$ https://www.folhape.com.br/sabores/e-tempo-de-caju-na-feira-e-no-prato/76213/>. Acesso em: 13 de fev. de 2021.

STEELE, E. M.; RAUBER, F.; COSTA, C. dos S.; LEITE, M. A.; GABE, K. T.; LOUZADA, M. L. da C.; LEVY, R. B.; MONTEIRO, C. A. Mudanças alimentares na coorte NutriNet Brasil durante a pandemia de covid-19. Revista de Saúde Pública, v. 54, p. 91, 2020. Disponível em: <https://www.revistas.usp.br/rsp/article/view/174857>. Acesso em: 3 mar. 2021.

TRZECIAK, D. Artesanato e receitas de butiá são fontes de renda no interior do RS. G1, 12 dez. 2012. Disponível em: <http://g1.globo.com/rs/rio-grande-do-sul/nossa- 
DE NORTE A SUL: UMA ANÁLISE SOBRE AS

CARACTERÍSTICAS ECONÔMICAS E GASTRONÔMICAS DAS PRINCIPAIS FRUTAS IDENTITÁRIAS NO BRASIL
Gabriela Ferreira Rodrigues Aline Gomes Santana Neide Kazue Sakugawa Shinohara

terra/2012/noticia/2012/12/artesanato-e-receitas-de-butia-sao-fontes-de-renda-nointerior-do-rs.html>. Acesso em 15 de mar. de 2021.

VELOSO, V. Na 34a edição, Festival da Jabuticaba de Sabará se reinventa. G1, 21 nov. 2020. Disponível em: <https:/g1.globo.com/mg/minas-gerais/noticia/2020/11/21/na-34a-edicaofestival-da-jabuticaba-de-sabara-se-reinventa.ghtml>. Acesso em 16 de mar. de 2021. 